\title{
Will artificial intelligence be a blessing or concern in assistive robots for play?
}

Oopen acess

${ }^{1}$ Faculty of Rehabilitation Medicine, University of Alberta, Canada

2UCP - Católica Lisbon School of Business \& Economics, Lisbon, Portugal

${ }^{3}$ Medicine and Health Sciences School, Universidad del Rosario, Bogota, Colombia

\section{Corresponding author:}

kdadams@ualberta.ca

Manuscript received: 05 May 2018 Manuscript accepted: 13 June 2018

Version of record online: 20 June 2018
Kim Adams ${ }^{1}$, Pedro Encarnação², Adriana M. Rios-Rincón ${ }^{1,3}$, Al M. Cook ${ }^{1}$

\begin{abstract}
The recent advances and popularity of artificial intelligence (Al) offer exciting possibilities to improve technology but they also raise concerns. In this paper, we use our research to present the potential benefits of using Al in assistive technology for children with disabilities to access play, and examine potential ethical concerns surrounding data required by $\mathrm{Al}$ algorithms. Since play is a key factor in child well-being and cognitive development, secondary disabilities mayariseasaconsequence ofmotorimpairments. Assistive robots for augmentative manipulation can be instrumental in providing children with physical disabilities play opportunities, but we need to take a principled and user-centered approach to technical innovations.
\end{abstract}

Keywords: artificial intelligence, machine learning, assistive robots, augmentative manipulation, play, children with disabilities. 


\section{INTRODUCTION}

Artificial Intelligence (AI) and Machine Learning (ML) techniques are being applied in many areas nowadays, even in our daily interactions with technology (e.g., Google search engine $)^{1}$. McCarthy ${ }^{2}$ defined AI as "the science and engineering of making intelligent machines that have the ability to achieve goals like humans do". ML is a subset of AI where algorithms "learn from data, without the need to be explicitly programmed"3. Assistive technologies for people with disabilities are starting to incorporate ML in the design, for instance in ambient assisted living ${ }^{4}$. We have had a long research program in assistive robotics for manipulation for children with disabilities to access play, and ML could be very beneficial in making the robots easier to use. However, using robots that involve ML could raise concerns for children and parents. There have been several instances covered in the media of situations where AI has made mistakes, e.g., self-driving car accidents ${ }^{5}$. Some people already mistrust robots in healthcare ${ }^{6}$ and adding the unknowns of AI, could make it worse. In this paper, we will briefly present our studies of children with disabilities accessing play via assistive robots to illustrate the potential of ML, discuss some concerns and identify some considerations we can apply as researchers and clinicians. This is an interesting application area since ML could make robots easier to use by children, but we also need to be vigilant about protecting them from harm.

Play, understood as "a range of voluntary, intrinsically motivated activities associated with recreational pleasure and enjoyment"7, is the most prevalent activity in childhood and has a critical role in child development. Through play children practice and show cognitive, motor, language, and social skills ${ }^{8,9}$. It provides them the opportunity to discover their own capabilities, to manipulate and try-out objects, to make decisions, to comprehend cause and effect relationships, to learn, to persist, and to understand consequences ${ }^{10,11}$. During play children learn about the properties of objects and how to interact with them ${ }^{12}$, and experience a sense of internal control and mastery ${ }^{13}$.

Children with disabilities may experience play deprivation due to their impairments along with physical and attitudinal barriers imposed by the context ${ }^{10}$. When children have motor disabilities that limit their ability to reach and grasp objects, or limit their ability to communicate their wishes and needs, they are limited in their exploration and play ${ }^{14}$. Physical environments including recreational facilities, toys, and play materials that are not specially designed or adapted for them, and attitudinal barriers imposed by people around children also contribute to play deprivation ${ }^{11,15}$.

These sources of deprivation can generate anxiety, frustration and passivity in children, which often leads to secondary disabilities, such as decreasing the child's senses of self-efficacy, self-confidence, satisfaction and well-being ${ }^{15}$, and ultimately learned helplessness, when children perceive themselves as spectators rather than actors $^{16}$. All of these situations delay, not only child's play and development, but also future functioning in educational, community and work contexts ${ }^{10}$.
Providing children who have disabilities with tools for aiding manipulation and the opportunities to use them can promote exploration and discovery and promote development. Robotic systems can be programmed to execute a wide variety of actions and are able to manipulate actual objects in the environment. The term augmentative manipulation has been used to refer to robots that are assistive manipulation devices for individuals with severe motor impairments ${ }^{17}$. For a survey of studies of assistive robots for augmentative manipulation for school or play activities $\operatorname{see}^{18}$.

\section{Our play studies}

Most of our assistive robot studies involved children with disabilities of various ages and disabilities engaging in structured activities. Cook et al. ${ }^{19}$ showed that children with disabilities with a cognitive age as young as 8 months were able to use a switch-controlled educational robotic arm as a tool to bring a cookie closer. Subsequently, an adapted industrial robotic arm was used by four 6 and 7-year-old children with severe motor impairments due to cerebral palsy to perform exploration and cooperative container play with an adult ${ }^{20,21}$. Children were able to actively engage in this activity and learn how to operate the robot using switches to perform the tasks, but they needed practice to carry out the most complex tasks. In another study, a three step, three switch, digging task was trialed with twelve 5 to 10 -year-old children with severe physical disabilities ${ }^{22}$. All of the participants were able to independently control at least two switches in the sequence.

The features of the educational and industrial robots such as size and weight, along with high cost, imposed constraints for conducting research or replication in schools or children's homes ${ }^{23}$. Thus, we began using Lego $^{\circledR}$ Mindstorms $^{\circledR}$ robots because they are relatively inexpensive and perceived as playful. Ten children from 4 to 10 years old with widely variable motor, cognitive and language abilities, used the Lego robotic systems in various activities $^{24}$. Structured tasks were used to see if children understood the function of the switches in controlling the robot, such as hitting a switch to make the robot draw a circle. Some children demonstrated understanding of up to four switches to drive the "roverbot" in various playful activities.

We also investigated the effect that having a Lego robot during unstructured play had on the level of children's playfulness, defined as the disposition to play ${ }^{25}$. Results showed that the use of the Lego robot increased playfulness in four children with cerebral palsy and, at the same time, decreased the directiveness that mothers had on their children's play ${ }^{26}$. However, children tended to only perform functional robot play (i.e. driving the robot around) rather than pretend play (i.e. pretending the robot was a zoo keeper). Figure 1 shows some of the robots used in our studies. 


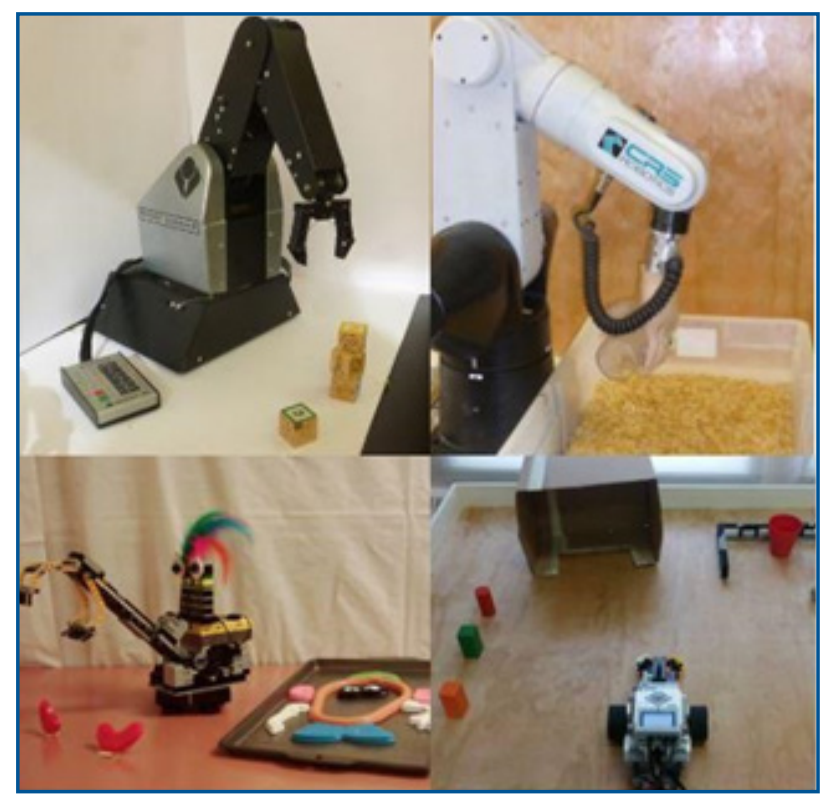

Figure 1: Various robot arms and mobile robots used in our studies

\section{Cognitive skills required to control robots}

Some children with disabilities in the studies above had trouble controlling all functions of the robot. Robot-assisted manipulation requires the understanding of tool use, which has been linked to the understanding of cause and effect, sequencing and prospective planning, and involves understanding and perceiving properties of objects in relation to self-goals and needs ${ }^{27,28}$.

We have examined the cognitive demands of using robots with typically developing children. Starting from the skills identified by Forman ${ }^{29}$ to control a robot arm (causality, spatial relations, binary logic, coordination of multiple variables, and reflectivity) we identified skills to control a switch-controlled mobile robot (cause and effect, inhibition, laterality, and sequencing). In Forman's and our studies, only older children, 5 years old in our case, mastered the more cognitively complex task ${ }^{30,31}$. We also ${ }^{32}$ observed if robotic manipulation could enable both functional and pretend play, for typically developing children, aged 3 to 7 years $^{32}$. When 3 and 4 -year-old children used their hands to play they easily performed pretend play. However, with the robot they resorted to functional play by driving the robot around. Thus, the demand of having to control the robot to manipulate the toys was interfering with their play.

The children with disabilities in the studies above had physical and cognitive limitations that affected their access and play. For instance, when the motor impairment was severe, children may have only had one or two anatomical sites that they could physically control to activate a switch as robot input. Children with brain-based disabilities may have had the cognitive understanding at the level of a younger typically developing child, thus they may have only understood the skill of cause and effect (hit a switch for the robot to move). However, only using one switch (e.g., for forward) or two switches (e.g., to turn one way or the other) does not take full advantage of the capability of the robot as a tool to interact with toys. Scanning through a set of robot controls may be too inefficient, or cognitively demanding, decreasing the level of playfulness. We need to make robots easier to control using a child's unique inputs and take advantage of the full functionality of the robot. The use of AI could help children with motor and cognitive impairments in performing the most difficult tasks when operating the robot. As a result, the challenge of the play activity may be more balanced with the children's skills. The presence of this balance is called the "flow channel" or the "flow state" ${ }^{33}$. This way children can have interesting play experiences and focus on their individual or group play activity, rather than on robot control.

\section{The promise and the concerns of Al}

To expand the possible input methods to control robots, we have been using ML algorithms that take brain signals and eye gaze as inputs. ML was used to classify surface electroencephalograph (EEG) signals of imagined movements into robot movements ${ }^{34}$. Plus, ML was used to determine a desired target toy from eye gaze, robot position, and reaction time data ${ }^{35}$. Using these natural behaviors to control a robot could reduce the need for the children to explicitly instigate a robot function (like when using a system where the user has to gaze at a button on a screen for a certain amount of time to make the robot command).

However, the use of the kind of data necessary for these ML algorithms raises the issue of data privacy. In order for ML algorithms to make good classifications, they need to learn from a lot of data. The brain-computerinterface (BCI) field is encouraged to share databases so multiple researchers can access the data to improve their algorithms, but ensuring participant confidentiality may be a substantial task in this context ${ }^{36}$. With the potential for the mainstream to expand the applications of BCI, researchers are calling for an international agreement to ensure people have a "private mental life", e.g., explicitly opt in to share neural data from any device ${ }^{37}$. Eye gaze cameras only record reflections off the cornea, but there are other input methods that we might consider that have higher privacy risks. For instance, a camera positioned to record a child's face could gauge emotions and adjust the demands of a task automatically. Parents could be very concerned about the risk of their child's image being shared outside the technology.

We have also used ML to optimize the robot functions available to the user. In the studies above, we used different degrees of autonomy to match the level of support the child needed. If the child was able to control all the system degrees of freedom, the robot was in a teleoperated mode (4 switches); if the child was able to control up to a certain number of movements, those movements triggered pre-recorded robot actions (e.g., the robot may turn 90 degrees upon a switch hit). The robot was even programmed to be in a fully autonomous mode, requiring no user intervention other than initiation to perform a sequence of actions. However, pre-programming takes time, so we are examining ML for the robot to automatically provide the correct level of autonomy for children to be successful in tasks. For example, in our mobile robot switch skills tasks, the system is detecting 
the performance of the children, and will perform the switch presses that the child does not. In another study, a joy-stick controlled robot is learning how physical "handover-hand" help is provided at the user interface by an aide and then applying that same help autonomously in subsequent iterations, without the aide needing to do $\mathrm{it}^{38}$. Robots can also have built in capabilities such as picking and placing an object, thus releasing the child from the low-level commands necessary to achieve high-level tasks. The robot system could adapt as the child learns to take on the tasks themselves. The robotic system could "grow with the child", taking over more functionality early and sensing changes in the child's skills and gradually turning full control over to the child as their capability increases. This would keep the child actively involved in using the tool.

However, this issue of autonomy can be of concern for parents due to responsibility and trust ${ }^{6}$. If the robot is fully autonomous, it may do a questionable function, one that an aide or the child would not want. The way decisions are made by the robot may not be known to the programmer or clinicians. The system could behave in ways that the child will not claim as their own ${ }^{37}$. An autonomous AI system could learn only some things, and never present the other options to the user ${ }^{39}$. Researchers and clinicians should inform children and parents about these issues, and a potential technical solution could be to use supervised autonomous interaction ${ }^{6}$.

A primary concern when dealing with personal robots and AI is safety. Special care is needed to build safety into the robotic systems, such as force sensors, cameras, and tactile sensors that stop the robot when they reach a threshold ${ }^{6}$. The International Organization for Standardization (ISO) 13482 is the international standards for safety requirements for personal robots.

\section{Future perspectives on $\mathrm{Al}$}

As we go forward, there will be many AI innovations that could potentially be beneficial to implement in assistive robots for augmentative manipulation. For instance, interfaces that accept the idiosyncratic gestures or natural language of children with disabilities could expand the available inputs for control of the robot. AI assistants or social robots could provide not only manipulation, but also a social play-mate. But, we will have to be cautious in our choices.
As in implementation of other complex assistive technology ${ }^{40}$, a client-centered, multi- or interdisciplinary approach will be needed by teams considering implementing AI to ensure perspectives of children, families, and health, science and social science professions are considered. We need to ensure that we are doing what is best for the child. Rather than just compensating for lost function (e.g., by having a robot do the full task autonomously), assistive robots should contribute to growth and independence for children with disabilities and thus aim for the "just-right" amount of autonomy. Improvements in technology should not be the goal, but improvements should be valued for how they can support goals in healthy development and functional independence ${ }^{41}$.

There are resources we can use to guide ethical technology design and clinical use, and we wihave to consider the ethics around both robots and AI. One example is Riek and Howard's code of ethics for human robot interaction, which covers human dignity, design, legal and social considerations ${ }^{42}$. Some of the concerns raised in this paper are covered in this code (the right to privacy, trustworthiness, transparent decision paths). The Asilomar artificial intelligence principles provide a guide to researchers, business leaders, and others ${ }^{43}$.

In order to guide an informed approach to the use of assistive robots with ML enhanced inputs and autonomy, we will need to critically examine the expectations, experiences and potential ethical implications for children and their families. We are looking forward to next steps in our research program involving qualitative research with ethicists to build the knowledge-base in this emerging area. We are living in interesting times, and many interesting conversations and collaborations will occur because of it.

\section{Acknowledgements}

The authors would like to acknowledge the financial support from the following funding agencies: Women and Children's Health Research Institute and the Stollery Children's Hospital Foundation; Glenrose Rehabilitation Hospital Foundation; Fundação para a Ciência e a Tecnologia (UID/GES/00407/2013), Portugal; Collaborative Health Research Project (CHRP), a joint initiative of the National Sciences and Engineering Research Council (NSERC) and Canadian Institutes of Health Research (CIHR) Grants 462227-14, 134744.

\section{REFERENCES}

1. Sullivan D. FAQ: All about the Google RankBrain algorithm. Google's using a machine learning technology called RankBrain to help deliver its search results. Here's what's we know about it. [cited 2018 May 15] Available from: https://searchengineland.com/faq-all-about-the-new-google-rankbrainalgorithm-234440.

2. McCarthy J, Hayes P. Some philosophical problems from the standpoint of artificial intelligence. In: Michie D. Machine intelligence. Elsevier, 1969; p.463.

3. Samuel AL. Some studies in machine learning using the game of checkers. IBM J Res Dev. 1959;3(3):210-29. DOI: http://dx.doi.org/10.1147/rd.33.0210

4. Rashidi $P$, Mihailidis A. A survey on ambient-assisted living tools for older adults. IEEE J Biom Health Informatics. 2013;17(3):579-90. DOI: http://dx.doi.org/10.1109/JBHI.2012.2234129

5. Stewart J. Tesla's autopilot was involved in another deadly car crash. [cited 2018 May 15] Available from: 
https://www.wired.com/story/tesla-autopilot-self-driving-crash-california/.

6. Cook AM, Alvarez L. Ethical and social implications of the use of robots in rehabilitation practice. In: P Encarnação, AM Cook (eds.) Robotic assistive technologies. CRC Press, 2017; p.349-74.

7. Garvey C. Play. Cambridge: Havard University Press, 1990.

8. Parham LD. Play in occupational therapy. In: Parham LD, Fazio LS (eds.) Play in occupational therapy for children. St. Luis, Missouri: Mosby; 2008.

9. Besio S, Caprino F, Laudanna E. Profiling robot-mediated play for children with disabilities through ICF$\mathrm{CY}$ : the example of the European project IROMEC. In: Miesenberger K, Klaus J, Zagler W, Karshmer A (eds.) Computers helping people with special needs. Lecture Notes in Computer Science, vol 5105. Springer, Berlin, Heidelberg: ICCHP, 2008.

10. Missiuna C, Pollock N. Play deprivation in children with physical disabilities: The role of the occupational therapist in preventing secondary disability. Am J Occup Ther. 1991;45(10):882-8. DOI: http://dx.doi. org/10.5014/ajot.45.10.882

11. Ferland F. The ludic model: play, children with physical disabilities, and occupational therapy. Canad J Occup Ther. 2007;74(3):194. DOI: http://dx.doi.org/10.1177/000841740707400307

12. Reilly M. Play as exploratory learning: Studies of curiosity behavior. Sage Publications; 1974.

13. Bundy AC. Assessment of play and leisure: delineation of the problem. Am J Occup Ther. 1993;47(3):217-22.

14. Musselwhite CR. Adaptive Play for Special Needs Children: Strategies to enhance communication and learning. San Diego: College-Hill Press; 1985.

15. Blanche El. Play in children with cerebral palsy: Doing with-not doing to. [cited 2018 May 15] Available from: https://pdfs.semanticscholar.org/8949/3bd40ec2f718a38550ddfa9a8f7edc30cb24.pdf

16. Harkness L, Bundy AC. The test of playfulness and children with physical disabilities. Occup Ther J Res. 2001;21(2):73-89. DOI: http://dx.doi.org/10.1177/153944920102100203

17. Cook AM, Cavalier AR. Young children using assistive robotics for discovery and control. Teach Excep Children. 1999;31(5):72-8.

18. Adams KD, Alvarez L, Rios-Rincon AM. Robotic systems for augmentative manipulation to promote cognitive development, play, and education. In: P Encarnação, AM Cook (eds.) Robotic assistive technologies. CRC Press, 2017; p.219-60

19. Cook AM, Hoseit P, Liu KM, Lee RY, Zenteno-Sanchez CM. Using a robotic arm system to facilitate learning in very young disabled children. IEEE Transact Biom Eng. 1988;35(2):132-7. DOI: http://dx.doi.org/10.1109/10.1351

20. Cook A, Howery K, Gu J, Meng M. Robot enhanced interaction and learning for children with profound physical disabilities. Technol Disabil. 2000;13:1-8.

21. Cook AM, Meng MQ, Gu JJ, Howery K. Development of a robotic device for facilitating learning by children who have severe disabilities. IEEE Trans Neural Syst Rehabil Eng. 2002;10(3):178-87. DOI: http://dx.doi.org/10.1109/TNSRE.2002.802877

22. Cook AM, Bentz B, Harbottle N, Lynch C, Miller B. School-based use of a robotic arm system by children with disabilities. IEEE Trans Neural Syst Rehabil Eng. 2005;13(4):452-60. DOI: http://dx.doi.org/10.1109/TNSRE.2005.856075

23. Cook A, Encarnação $P$, Adams K. Robots: assistive technologies for play, learning and cognitive development. Technol Disabil. 2010;22(3):127-45. DOI: http://dx.doi.org/10.3233/TAD-2010-0297

24. Cook A, Adams K, Volden J, Harbottle N, Harbottle C. Using Lego robots to estimate cognitive ability in children who have severe physical disabilities. Disabil Rehabil Assist Technol. 2011;6(4):338-46. DOI: http://dx.doi.org/10.3109/17483107.2010.534231

25. Skard LS. Test of playfulness. In: Parham D, Fazio L (eds.). Play in occupational therapy for children. 2008; p.71-93.

26. Ríos-Rincón AM, Adams K, Magill-Evans J, Cook A. Playfulness in children with limited motor abilities when using a robot. Phys Occup Ther Pediatr. 2016;36(3):232-46. DOI: http://dx.doi.org/10.3109/01942638.2015.1076559

27. McCarty ME, Clifton RK, Chollard R. The beginnings of tool use by infants and toddlers. Infancy. 2001;2(2):233-56.

28. Buttelmann D, Carpenter M, Call J, Tomasello M. Rational tool use and tool choice in human infants and great apes. Child Dev. 2008;79(3):609-26. DOI: https://doi.org/10.1111/j.1467-8624.2008.01146.x

29. Forman G. Observations of young children solving problems with computers and robots. J Res Child 
Educ. 1986;1(2):60-74. DOI: https://dx.doi.org/10.1080/02568548609594908

30. Encarnação P, Alvarez L, Rios A, Maya C, Adams K, Cook AM. Using virtual robot mediated play activities to assess cognitive skills. Disabil Rehabil Assist Technol. 2014;9(3):231-41. DOI: https://dx.doi.org/10.3109/17483107.2013.78257

31. Poletz L, Encarnação P, Adams K, Cook AL. Robot skills and cognitive performance of preschool children. Technol Disabil. 2010;22(3):117-26. DOI: https://dx.doi.org/10.3233/TAD-2010-0296

32. Adams KD, Rios-Rincon AM, Puyo LMB, Cruz JLC, Medina MFG, Cook AM, et al. An exploratory study of children's pretend play when using a switch-controlled assistive robot to manipulate toys. $\mathrm{Br} \mathrm{J}$ Occup Ther. 2017;80(4):216-24. DOI: https://dx.doi.org/10.1177/0308022616680363

33. Csikszentmihalyi M. Flow: the psychology of optimal experience. New York: Harper \& Row; 1990.

34. Sakamaki I, Tavakoli M, Adams K. Generating forbidden region virtual fixtures by classification of movement intention based on event-related desynchronization. IEEE Global Conference Signal Inform Proc. Canada: 2017.

35. Castellanos JL, Gomez MF, Adams KD. Using machine learning based on eye gaze to predict targets: An exploratory study. IEEE Symposium Series Comp Intelligence. 2017; DOI: https://dx.doi.org/10.1109/SSCI.2017.8285207

36. Schneider MJ, Fins J, Wolpaw J. Ethical issues in BCI research. In: Wolpaw JR, Wolpaw EW(eds.). Brain-computer interfaces: principles and practice. New York: Oxford; 2012.

37. Yuste R, Goering S, Arcas BA, Bi G, Carmena JM, Carter A, et al. Four ethical priorities for neurotechnologies and Al. Nature. 2017;551:159-63. DOI: https://dx.doi.org/10.1038/551159a

38. Najafi M, Sharifi M, Adams K, Tavakoli M. Robotic assistance for children with cerebral palsy based on learning from tele-cooperative demonstration. Int J Intellig Robotics Applicat. 2017;1(1):43-54. DOI: https://dx.doi.org/10.1007/s41315-016-0006-2

39. Friedrich $\mathrm{O}$, Racine E, Steinert S, PömsI J, Jox RJ. An analysis of the impact of brain-computer interfaces on autonomy. Neuroethics. 2018;1-13. DOI: https://dx.doi.org/10.1007/s12152-018-9364-9

40. Cook AM, Polgar JM. Cook \& Hussey's assistive technologies: principles and practice. Philadelphia: Elsevier; 2007.

41. Sulivan LS, Illes J. Ethics in published brain-computer interface research. J Neural Eng. 2018;15(1):013001. DOI: https://dx.doi.org/10.1088/1741-2552/aa8e05

42. Riek L, Howard D. A code of ethics for the human-robot interaction profession. [cited 2018 May 15] Available from: http://robots.law.miami.edu/2014/wp-content/uploads/2014/03/a-code-of-ethics-for-thehuman-robot-interaction-profession-riek-howard.pdf.2014

43. Future of Life Institute. Asilomar Al principles. [cited 2018 May 15] Available from: https://futureoflife.org/ ai-principles/.

\section{Resumo}

Os avanços recentes e popularidade da Inteligência Artificial (IA) oferecem possibilidades animadoras para melhorar a tecnologia, mas, também, trazem preocupação. Neste artigo, usamos nossa pesquisa para apresentar os benefícios potenciais do uso da IA em tecnologia assistiva para crianças com deficiências brincarem e examinar possíveis preocupações éticas em torno dos dados exigidos pelos algoritmos de IA. Uma vez que o brincar é um fator chave no bem-estar infantil e no desenvolvimento cognitivo, as incapacidades secundárias podem surgir como consequência de deficiências motoras. Robôs assistivos para manipulação aumentativa podem ser fundamentais para proporcionar às crianças com deficiência física oportunidades de brincar, mas precisamos adotar uma abordagem baseada em princípios e centrada no usuário para inovações técnicas.

Palavras-chave: inteligência artificial, machine learning, robôs assistivos, manipulação aumentativa, brincar, crianças com deficiências.

${ }^{\odot}$ The authors (2018), this article is distributed under the terms of the Creative Commons Attribution 4.0 International License (http:// creativecommons.org/licenses/by/4.0/), which permits unrestricted use, distribution, and reproduction in any medium, provided you give appropriate credit to the original author(s) and the source, provide a link to the Creative Commons license, and indicate if changes were made. The Creative Commons Public Domain Dedication waiver (http://creativecommons.org/publicdomain/zero/ $1.0 /$ ) applies to the data made available in this article, unless otherwise stated. 